\title{
Cyber-Physical System of a Solid Oxide Fuel Cell/Micro Gas Turbine Hybrid Power Plant
}

\author{
Anna Marcellan ${ }^{1}{ }^{*}$, Alessio Abrassi ${ }^{2}$, and Marius Tomberg ${ }^{3}$ \\ ${ }^{1}$ Institute of Combustion Technology, German Aerospace Center (DLR), Pfaffenwaldring 38-40, 70569 \\ Stuttgart, Germany \\ ${ }^{2}$ Thermochemical Power Group (TPG), University of Genoa, Viale Cambiaso 4, 16145, Genova, Italy \\ ${ }^{3}$ Institute of Engineering Thermodynamics, German Aerospace Center (DLR), Pfaffenwaldring 38-40, \\ 70569 Stuttgart, Germany
}

\begin{abstract}
A hybrid power plant combining a solid oxide fuel cell (SOFC) and a micro gas turbine (MGT) is a suitable technology solution for decentralized energy production utilizing natural gas and biogas. Despite having high electrical efficiency and low emissions, the dynamic interactions between components can lead to damages of the system if a comprehensive control strategy is not applied. Before building a coupled hybrid power plant demonstrator, the "hybrid system emulators" approach is followed to solve any integration issues. A test rig consisting of an MGT and emulated SOFC is developed. The dynamics of the SOFC are reproduced by a real time model. The created cyber-physical system provides an effective platform to validate and optimize the control concepts for the future hybrid demonstrator by adding the complexity of the hybrid plant to the MGT test rig. The ability to develop and test the control strategy on such a system dramatically reduces the technology risk and increases the chances of success for the demonstrator operation.
\end{abstract}

\section{Introduction}

A hybrid power plant consisting of the combination of a solid oxide fuel cell (SOFC) and a micro gas turbine (MGT) is a technology concept that can operate with both natural gas and biogas, promising electrical efficiency above $60 \%[1,2]$. NOx emissions below $10 \mathrm{ppm}$ and $\mathrm{CO}$ emissions below $20 \mathrm{ppm}$ have been demonstrated for this type of system [3] and the high-temperature exhaust gases can be useful for cogeneration [4]. As a consequence, hybrid SOFC/MGT concepts have been extensively studied [5-7]. However, as a result of the high capital cost required to build hybrid demonstrators, only few studies include experimental data where measured efficiencies are usually lower than expected [5-11]. Only Mitsubishi Hitachi Power Systems, Ltd. (MHPS) has commissioned hybrid power plant demonstrators $[12,13]$; however, no experimental data has been reported.

Hybrid systems pose many challenges with regard to system controls and component integration. This is due to the elaborate system configurations and subsystems interactions,

* Corresponding author: anna.marcellan@dlr.de 
which lead to complex transient dynamics and difficult control tasks [14, 15]. Preliminary research results [16] highlight the relevance of differing subcomponent characteristics on system operation, and therefore on the control strategy development of the plant. The control concept should be able to handle undesired conditions and guarantee the survivability of the plant and personnel safety. However, testing robustness and effectiveness of control strategies on hybrid plant demonstrators is expensive and involves high risks [11]. Moreover, the numerical models developed thus far are difficult to validate due to the lack of sufficient experimental data $[8,17,18]$. Therefore, system dynamics and subsystems interactions during transient manoeuvers are still an opaque topic. Despite the potential of the hybrid plant, the risks and impacts of the SOFC operation on the MGT and vice versa remains one major obstacle in bringing this technology to the present market.

The current study intends to explore how micro gas turbine hybrid power plants can potentially leverage efficiency and reliability based on a cyber-physical system. A concept for a $33 \mathrm{~kW}_{\mathrm{el}}$ SOFC/MGT [19] hybrid power plant demonstrator (HyPP) has been developed. It combines an MGT producing $3 \mathrm{~kW}_{\mathrm{el}}$ with a planar SOFC supplying $30 \mathrm{~kW}_{\mathrm{el}}$. To investigate the effects of each system on the other, the "hybrid system emulators" approach is pursued. A test rig which includes MGT components and emulates the effects of the SOFC has been developed. The hybrid system emulator method has already been used by other research institutes in order to validate the concept of the hybrid plant [20-24]. The research concerns outlined above are addressed with the development of a cyberphysical system, a strategy that brings together the advantages of numerical models and hardware components [8]. Additionally, a real time dynamic model of the fuel cell system is developed. The model is connected to the MGT and emulated SOFC components. By reading and writing values from/to the plant, the model allows for the assessment of the hybrid system performance under various operating conditions and for the identification of non-intuitive behaviour caused by the interactions between subcomponents. Moreover, the real time model is integrated in the control strategy developed for the hybrid demonstrator, where the effectiveness of control methods can therefore be tested and evaluated, as shown in previous works [25]. This paper aims to describe the integration of the developed control strategy for the HyPP concept at DLR by creating a cyber-physical system from the MGT test rig.

\section{Hybrid Power Plant (HyPP) concept and control strategy}

For HyPPs, several configurations are possible [26, 28]. At the DLR, the directly coupled configuration shown in Fig. 1 is being investigated. In this configuration, the combustion chamber of the gas turbine is partly substituted by the fuel cell. Therefore, a large amount of the fuel is oxidized in the fuel cell, resulting in high electrical system efficiency. A recirculation blower provides water and heat to the reforming reaction in front of the fuel cell module. Air is compressed in the compressor of the micro gas turbine, preheated by the turbine off-gases and enters the cathode inlet of the SOFC module. Both anode and cathode off-gases enter the combustor and are subsequently burned. The flue gas is then expanded in the turbine and drives the compressor and the generator.

For all operating points, the SOFC has to provide an adequate amount of energy to the combustor in order to safely run the gas turbine. Too much energy will result in excessive temperatures and can damage downstream components. If not enough energy is provided to the combustor, a flame out or too low cathode inlet temperatures can occur. In order to achieve a stable operation, a reliable control strategy is necessary. 


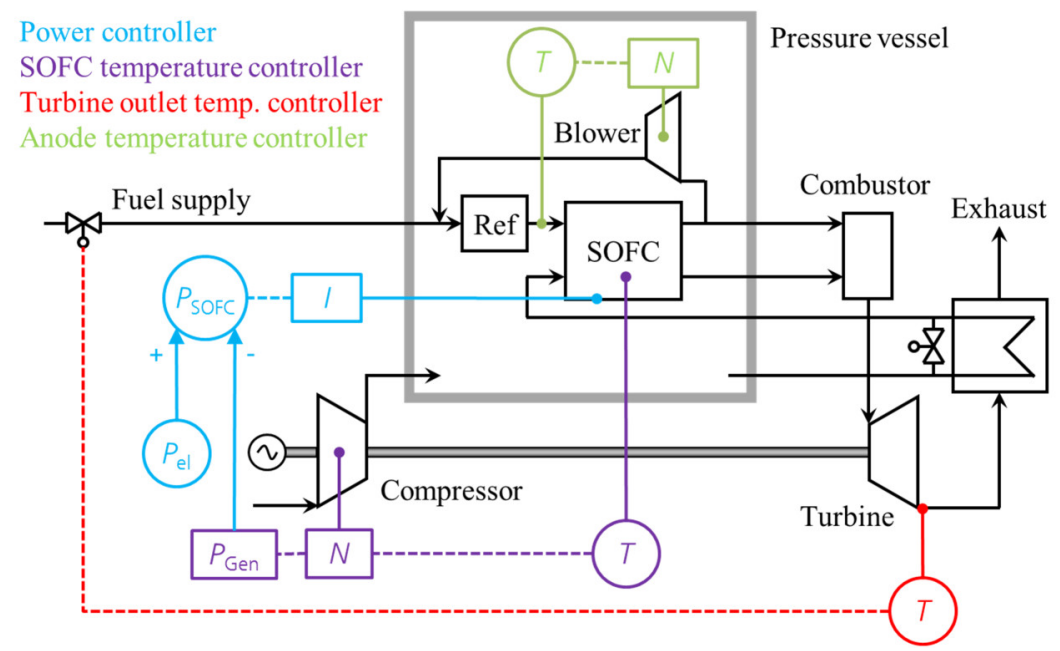

Fig. 1. Simplified plant layout and the most important control loops (modified from [25])

The control system is based on different PI controllers [27]. The control loops will be implemented in the test rig and the final parametrization will be done during commissioning of the system. Guesses for the control parameters can be derived from the "hybrid system emulators". Fig. 1 shows the control loops needed for the control of the hybrid power plant. If necessary, the PI controllers can be enhanced by a derivative part or a feed forward element. The total electrical power $\left(P_{\mathrm{el}}\right)$ is set by the operator and consists of the power output of the MGT generator $\left(P_{\mathrm{Gen}}\right)$ and the SOFC $\left(P_{\mathrm{SOFC}}\right)$. The power controller changes the electrical current of the fuel cell module $(I)$ to reach the desired power. The generator power is a disturbance value for the power controller and depends on the SOFC temperature controller that cools the fuel cell via the cathode mass flow. Therefore, the SOFC temperature controller modifies the rotational speed $(N)$, and thus controls the load point of the MGT, resulting in a higher or lower generator power. If the SOFC power or the SOFC temperature is changed, the turbine outlet temperature controller will change the fuel mass flow to keep the turbine outlet temperature constant. Thereby the anode temperature controller has to modify the recirculation blower speed $(N)$ to reach the anode inlet temperature set point and provide enough steam and heat for the reforming reaction.

\section{Hybrid system emulator: the MGT test rig}

Fig. 2 shows the MGT test rig layout with a description of the main components utilized in the SOFC emulation. In the main path, compressed air from the MGT centrifugal compressor enters the pressure vessel simulator and the first electric heater. The pressure vessel simulator is used to reproduce the free volume of the SOFC pressure vessel, while the heater emulates the increment of temperature due to the heat exchange with the hot core of the fuel cell. Next, the airflow enters the recuperator, where it exchanges heat with the hot exhaust gas from the turbine. Then, the preheated air enters the cathode emulator, which consists of a second electric heater, and is further directed into the combustor, or off-gas burner (OGB), where it reacts with the injected fuel. The combustion products expand through the turbine and exit the system after passing through the hot side of the recuperator.

The control strategy for the emulator test rig derives from the HyPP control concept. Different control loops based on PI and PID controllers have been parametrized and 
successfully tested. A feed forward turbine outlet temperature (TOT) controller was implemented and displayed good performance during transient maneuvers [23].

In the next step, the impact of the real SOFC behaviour to the MGT behaviour is added through the SOFC real time model implemented into the control strategy. Fig. 3 shows the control loops which are connected to both the hardware and the model. The shaft rotational speed (control loop 1 in Table 1), and therefore the air mass flow entering the system, is controlled through the turbine manufacturer software. A separate fuel supply provides natural gas directly to the combustion chamber, thus controlling the turbine outlet temperature (control loop 2). Control loop 3 defines the settings of the heater to achieve the necessary cathode outlet temperatures.

Table 1 MGT emulator test rig and control loops.

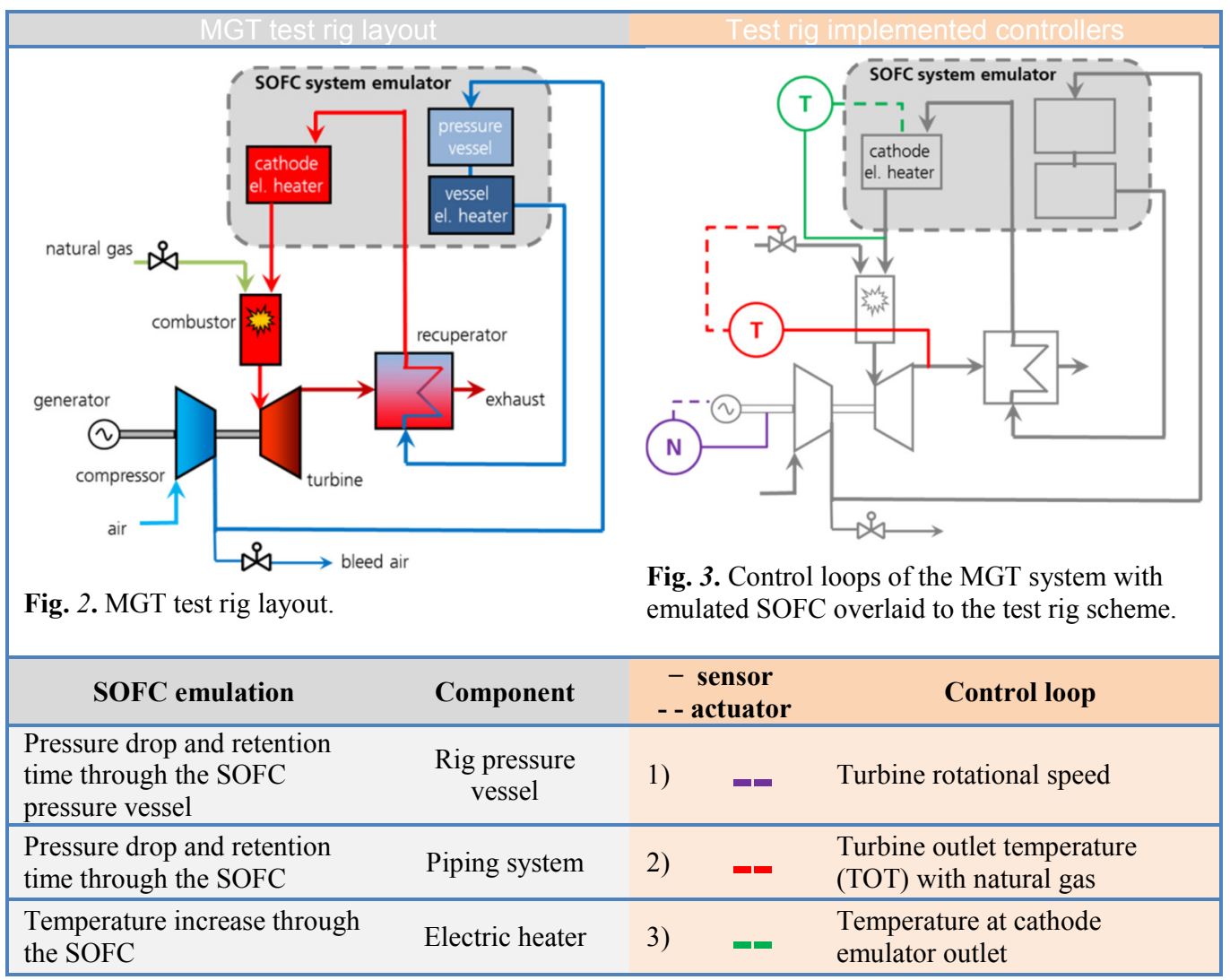

\section{Model layout and connections}

The model used on this plant was realized with Real-Time software developed by the Thermochemical Power Group (TPG) at University of Genoa. The modular software tool was developed in a Matlab ${ }^{\circledR}$ Simulink environment, capable of simulating complex plant layouts with reduced computational effort, allowing for it to be used for real-time applications. This specific model is characterized by a ratio between simulated time and actual time, which is less than one. Due to this calculated ratio and for other concerns, it was decided to keep the model in the Matlab ${ }^{\circledR}$ environment connected to the system during operation. Therefore, it was not chosen to proceed with the creation of an executable file. 
Utilizing an executable file would have improved computational performances; however, it would have also made access to the model more complex.

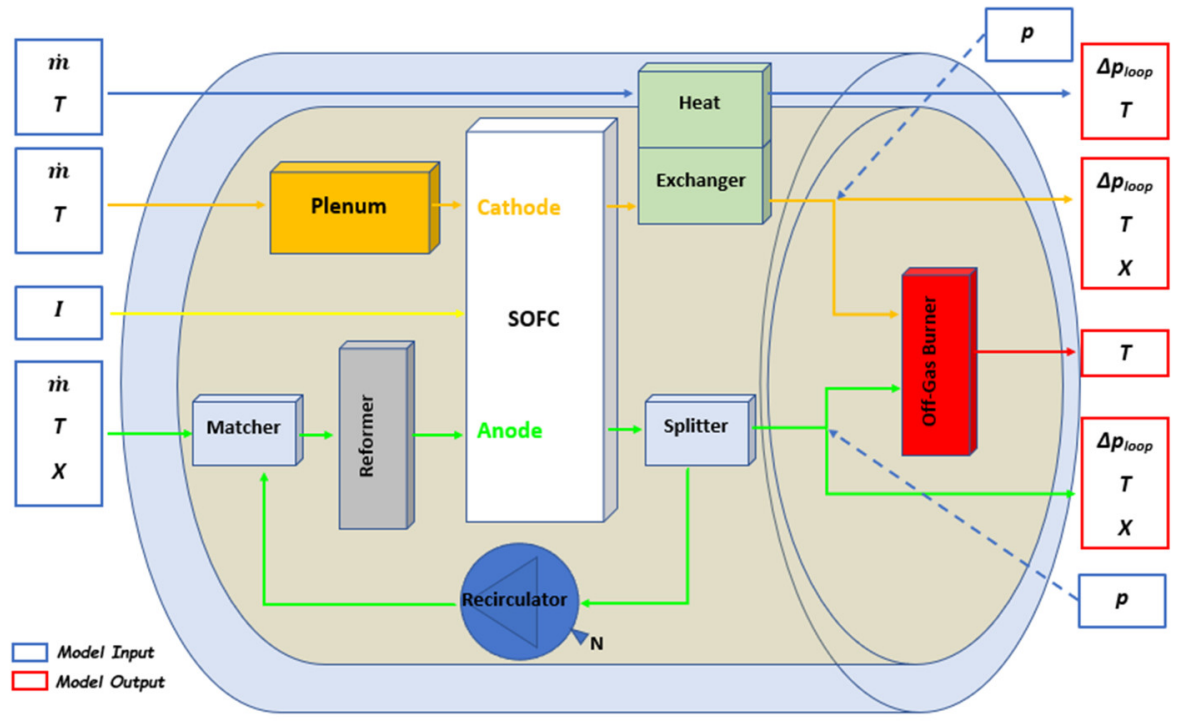

Fig. 4. Model layout: components and signals.

A Real-Time Pacer was inserted to guarantee real time execution of the model. The difference between the simulated time and elapsed real time is approximated, with expected differences on the order of 10 to 30 milliseconds. Fig. 4 displays the model layout, including the simulated components and signal management between the hardware and software. Each input is filtered with a moving average in order to attenuate any high frequency noise present in the measured signals. The modular approach of this tool requires that each physical component is represented by an independent Simulink block, which was developed following the lumped-volume approach. The components communicate via vectors containing information on the current thermodynamic conditions of the fluid that passes through them. The vectors correlate to signals for flow rate $(\dot{m})$, pressure $(\mathrm{p})$, temperature $(T)$, specific heat at constant pressure $\left(c_{p}\right)$, gas constant $(R)$ and lower heating value $(\mathrm{LHV})$.

\section{Results and Discussion}

The turbine outlet temperature (TOT) controller is of critical importance for this system. The thermal limit of the TOT protects the turbine exhaust section and the recuperator from damage due to excessive temperatures. Therefore, a controller which constrains the TOT by adjusting the natural gas mass flow to the combustion chamber is required.

First, the controller is connected to the test rig and parametrized. It adjusts the natural gas mass flow to the combustion chamber in order to lessen the difference between the real turbine inlet temperature (TIT) and the turbine inlet temperature calculated from the operator set point. Turbine rotational speed $(\mathrm{N})$ and the heater set point (cathode temperature emulator) are set directly by the operator. Then, the model is integrated into the loop, obtaining the "cyber-physical system". The controller compares the set value for the TOT and the real one, adjusting the fuel utilization (FU) of the SOFC model accordingly. Based on the desired SOFC generated current $\left(\mathrm{I}_{\text {set }}\right)$ and the type of fuel (LHV) used by the 
SOFC, the fuel mass flow to the anode is set. With the model output (anode and cathode mass flow, composition and temperature), the TIT is calculated and compared to the actual turbine inlet temperature. Based on the difference between the two turbine inlet temperatures, the amount of natural gas to the combustion chamber is controlled.

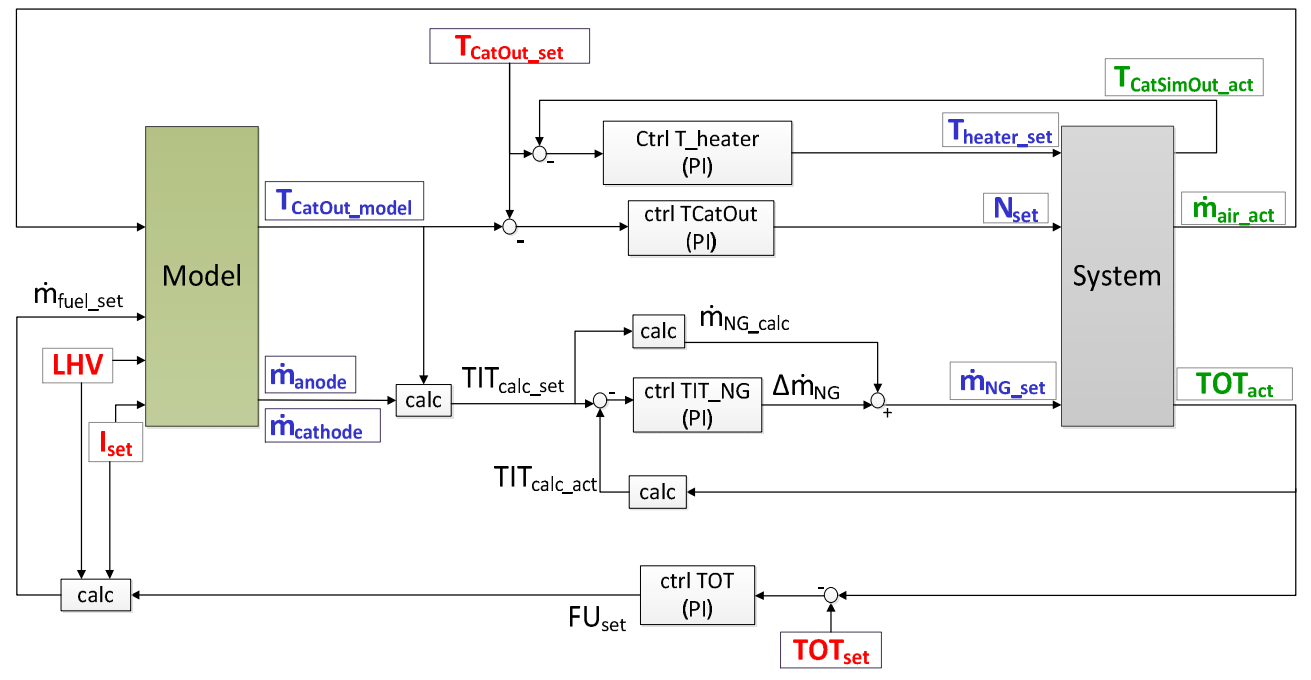

Fig. 5. TOT and turbine rotational speed controller connected to the test rig and to the model.

Finally, both the TOT controller and the cathode temperature controller are connected (Fig. 5). Here, the turbine air mass flow, and therefore cathode inlet flow, is read by the model. The model determines the cathode outlet temperature, which is compared to the set point value given by the operator. Based on the difference between cathode outlet temperatures, the controller adjusts the turbine rotational speed $(\mathrm{N})$, and therefore the airflow into the system. Lastly, the electric heater emulating the air temperature rise through the cathode is controlled by an inner loop.

Table 2 shows the results of a rotational speed step increase, which can be regarded as a disturbance to the system steady state. Both the model dynamic response and the hardware reaction are described. The effects of changing the TOT set point to the controller are investigated and the results are shown in Table 3 . The TOT set point is reduced and set again to the original value, and the dynamic response of the model is presented.

The cyber-physical system is used to test the effects of possible system disturbances or dynamic manoeuvers to the plant. Increasing the turbine rotational speed is required for when the operator needs to vary the SOFC core temperature. Therefore, for this case, it was observed that for a constant SOFC current set point and TOT set point, the control system needs to reduce the FU of the SOFC system, as more fuel is required.

However, a TOT set point reduction causes an initial cathode temperature increase. This should be taken into account when larger TOT set point variations are required. In order to keep the stack temperature constant, the cathode temperature controller is programmed to vary the turbine rotational speed (and therefore the airflow entering the SOFC). The change in airflow, in turn, will trigger a reaction from the TOT controller. A possible strategy for avoiding controller dynamic interaction is integrating a TOT set point ramp to the controller, reducing the TOT's influence on cathode temperature. 
Table 2. Cyber-physical system with active TOT controller: reaction to turbine rotational speed steps.

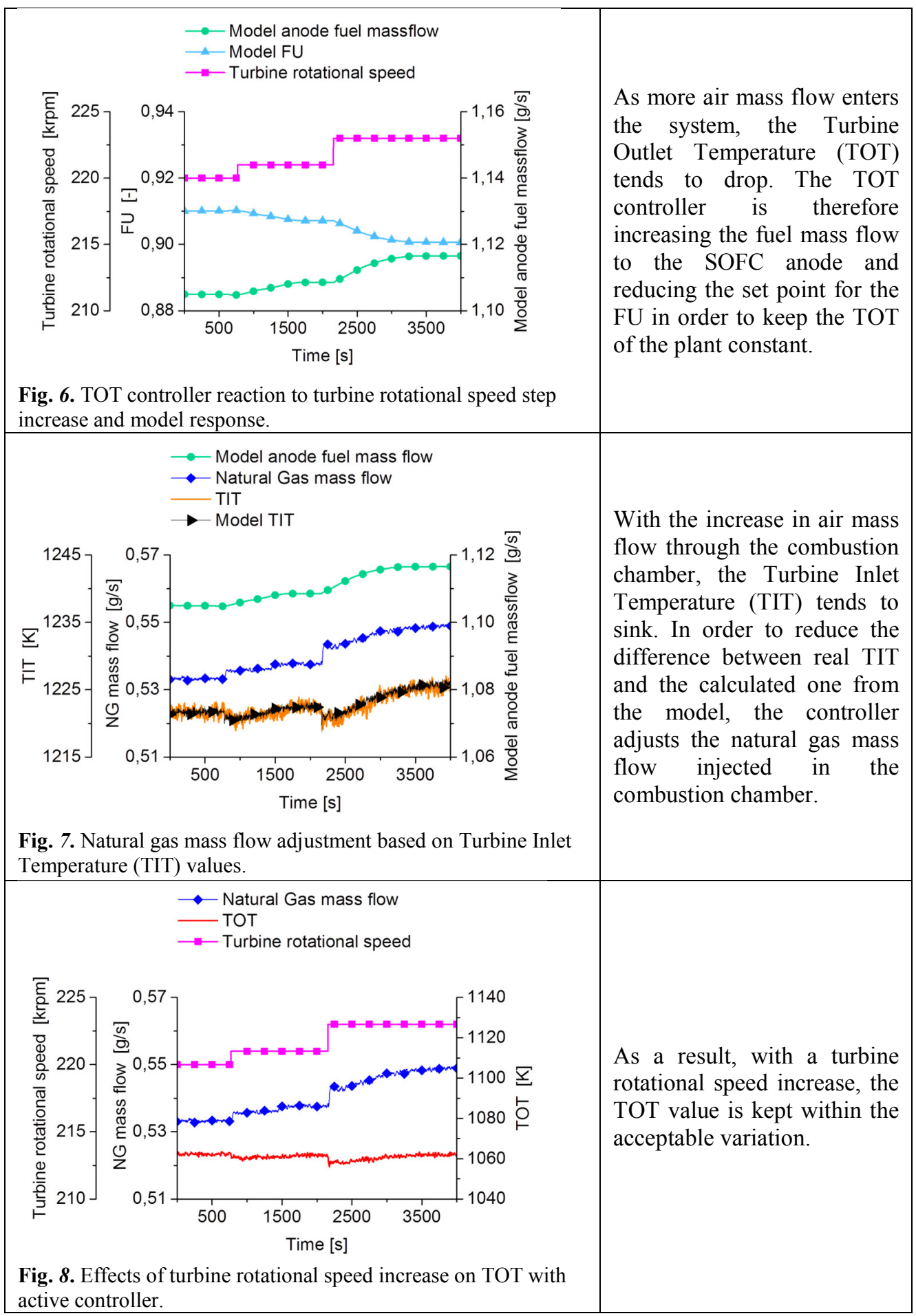


Table 3. Cyber-physical system reaction to TOT controller set point variation.

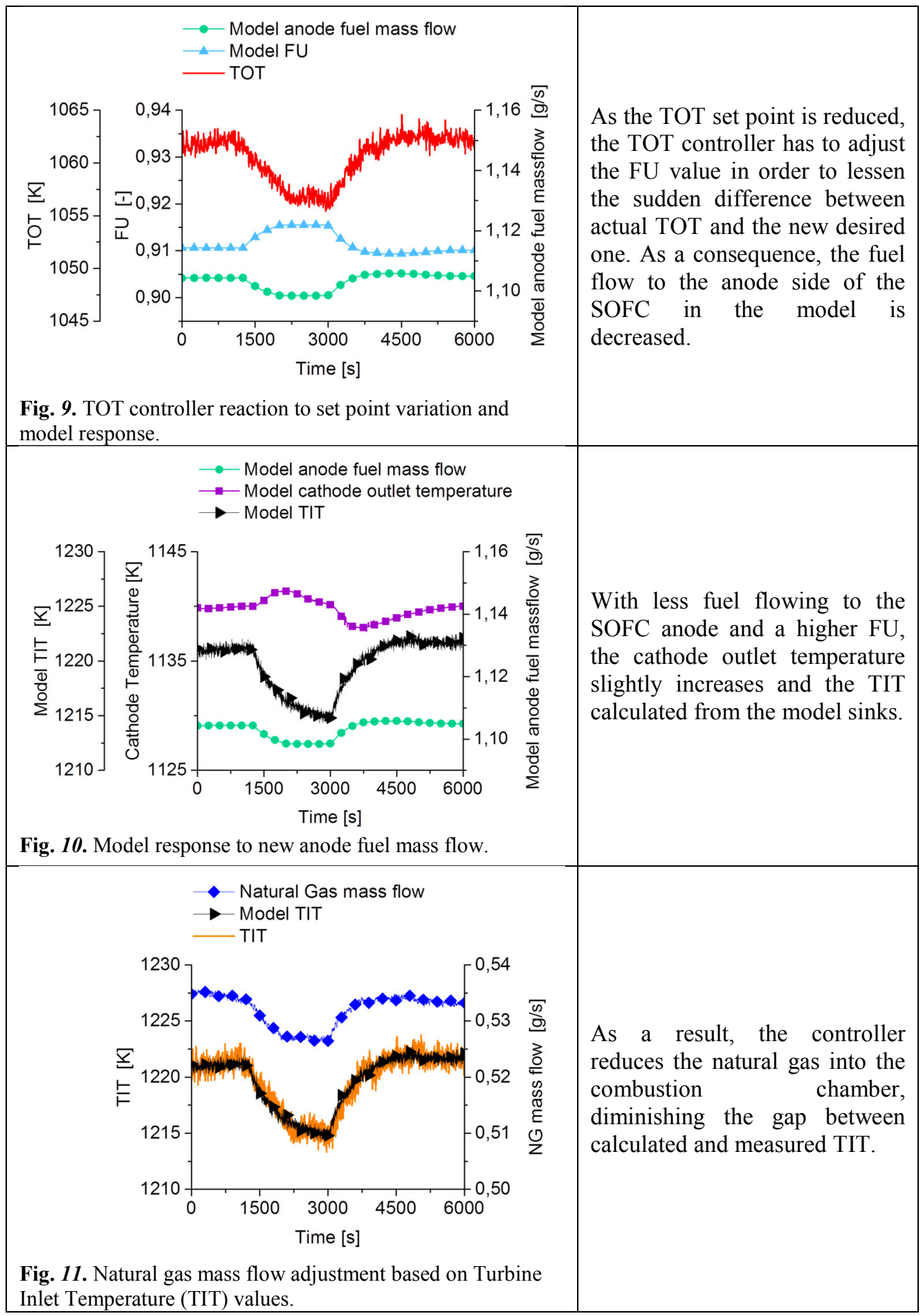




\section{Conclusions and Outlook}

A cyber-physical system consisting of an MGT test rig and an SOFC model has been constructed to reproduce the dynamic behaviour of the hybrid power plant concept developed at DLR. The model simulates the real time behaviour of all the SOFC related components of the hybrid plant. MGT system components, such as the power module with turbocomponents, recuperator, power electronics, combustion chamber, piping and emulating devices have been connected to the model through an OPC interface (OLE (Object Linking and Embedding) for Process Control).

The turbine outlet temperature controller and the stack temperature controller of the HyPP concept were successfully developed and tested using the cyber-physical system. The system reaction helped define optimization strategies for the hybrid plant control concept. The integration of the hardware and model shows high potential for developing and testing control system strategies and control loop interactions before implementation into the hybrid system demonstrator. After the integration of the optimized components into the test rig, the remaining control loops will be added to the control scheme and the interaction between controllers will be tested in the cyber-physical system.

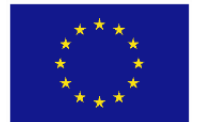

This project has received funding from the European Union's Horizon 2020 research and innovation programme under grant agreement No 641073 (www.bio-hypp.eu).

Furthermore, the support from the German Federal Ministry of Economic Affairs and Energy for the project "DemoHydra" is gratefully acknowledged. (Support code: 03ET6032).

\section{References}

1. T. Krummrein, M. Henke, P. Kutne, M. Aigner, Appl. En., 232, 598-606 (2018).

2. M. Henke, M. Steilen, C. Schnegelberger, M. Riedel, M. Hohloch, S. Bücheler, K. A. Friedrich, ECS Transactions, 68(1), 85-88 (2015).

3. T. Lingstädt, F. Grimm, T. Krummrein, P. Kutne, M. Aigner, AIAA, 1677 (2019).

4. L. Larosa, A. Traverso, M. L. Ferrari, V. Zaccaria, J. of Eng. for Gas Tur. and Power, 137(3), 031602 (2015).

5. A. Buonomano, F. Calise, M. D. d'Accadia, A. Palombo, M. Vicidomini, Appl. En., 156, 32-85 (2015).

6. A. Cuneo, V. Zaccaria, D. Tucker, A. Sorce, Appl. En., 230, 855-864 (2018).

7. M. L. Ferrari, A. Traverso, A. F. Massardo, Appl. En., 162 622-630 (2016).

8. T. P. Smith, Doctoral dissertation, Georgia Institute of Technology (2007).

9. S. E. Veyo, W. L. Lundberg, S. D. Vora, K. P. Litzinger, ASME, 649-655 (2003).

10. K. P. Litzinger, S. E. Veyo, L. A. Shockling, W. L. Lundberg, ASME, 669-676 (2005).

11. T. H. Lim, R. H. Song, D. R. Shin, J. I. Yang, H. Jung, I. N. C. Vinke, S. S. Yang, Int. J. of Hy. E., 33(3), 1076-1083.

12. Y. Ando, H. Oozawa, M. Mihara, H. Irie, Y. Urashita, T. Ikegami, Mitsubishi Heavy Industries Technical Review, 52(4), 47-52 (2015).

13. H. Irie, K. Miyamoto, Y. Teramoto, T. Nagai, R. Endo, Y. Urashita, Mitsubishi Heavy Ind Tech Rev, 54 (2017). 
14. J. Hasikos, H. Sarimveis, P. L. Zervas, N. C. Markatos, J. of Power Sources, 193(1), 258-268 (2009).

15. N. Zhou, C. Yang, D. Tucker, P. Pezzini, A. Traverso, Inter. J. of Hy. E., 40, 1967-1979 (2015).

16. A. Marcellan, M. Hohloch, M. Herbst, T. Lingstädt, T. Krummrein, M. Henke, M. Aigner, AIAA, 1676 (2019).

17. R. A. Roberts, J. Brouwer, J. of F. C. Sc. and Tech., 3(1), 18-25 (2006).

18. M. Steilen, C. Saletti, M. P. Heddrich, K. A. Friedrich, Appl. En., 211, 479-491 (2018)

19. M. Henke, M. Steilen, C. Schnegelberger, M. Riedel, M. Hohloch, S. Bücheler, K.
A. Friedrich, ECS Transactions, 68(1), 85-88 (2015).

20. D. Tucker, E. Liese, J. VanOsdol, L. Lawson, R. S. Gemmen, ASME 2002 Int. M. E. C. and E., 183-190 (2002).

21. D. Tucker, M. Shelton, A. Manivannan, The Electroc. Soc. Interf., 18(3), 45 (2009).

22. M. L. Ferrari, M. Pascenti, L. Magistri, A. F. Massardo, J. of F. C. Sc. and Tech., 7(2), 021005 (2010).

23. M. L. Ferrari, M. Pascenti, A. Traverso, A. F. Massardo, Appl. En., 97, 809-815 (2012).

24. P. Pezzini, F. Caratozzolo, A. Traverso, ASME Turbo Expo, 113-121 (2011).

25. L. Larosa, A. Traverso, M. L. Ferrari, V. Zaccaria, J. of Eng. for Gas Turb. and Power, 137(3), 031602 (2015).

26. M. Henke, Doctoral dissertation, University of Stuttgart (2015).

27. M. Henke, M. Steilen, R. Näke, M. Heddrich, K. A. Friedrich, 12th European SOFC \& SOE Forum (2016).

28. R. J. F. van Gerwen, Systems and Applications, In S. C. Singhal, \& K. Kenndall, High Temperature Solid Oxide Fuel Cells: Fundamentals, Design and Applications, 363-393, Elsevier Ltd (2003). 